\title{
PROJETOS DE VIDA NA VELHICE
}

\author{
Carla da Silva Santana
}

Marina Soares Bernardes²

Amanda Marcório Touro Blanco Molina ${ }^{3}$

resumo

Objetivo: Identificar os projetos de vida de idosos em curto, médio e longo prazo, bem como as pessoas envolvidas nestes projetos e a percepção de importância dada. Materiais e método: Estudo quanti-qualitativo, exploratório e transversal. Os instrumentos utilizados na coleta de dados foram: 1) Mini Exame do Estado Mental; 2) Questionário Pfeffer de Avaliação Funcional - QPAF; 3) Questionário socioeconômico; e 4) Questionário de identificação dos projetos de vida na velhice. A análise de dados foi realizada de maneira descritiva por análise de conteúdo. Resultados: Participaram 150 idosos, sendo 106 mulheres e 44 homens, com média de idade de 74 anos.

1 Graduada em Terapia Ocupacional. Doutora em Psicologia Escolar e do Desenvolvimento Humano. Professora Doutora da Universidade de São Paulo (USP), vinculada ao Departamento de Neurociências e Ciências do Comportamento. E-mail: carla.santana@fmrp.usp.br.

2 Graduada em Terapia Ocupacional. Mestre em Ciências. Doutoranda do Programa de Pós- Graduação Interunidades em Bioengenharia EESC/FMRP/IQSC - Universidade de São Paulo. E-mail: marina.bernardes@usp.br.

3 Graduada em Terapia Ocupacional pela Faculdade de Medicina de Ribeirão Preto - Universidade de São Paulo. E-mail: amanda.molina@usp.br. 
Destes, 41 referem não projetar o futuro, pois acreditam que isto é algo que deva ser feito pelos jovens. Para aqueles que o fazem, em curto e médio prazo destacam-se os projetos relacionados ao lazer e participação social, econômico e convívio familiar. A manutenção da saúde e do bem-estar físico aparece como contínuo ao longo do tempo; 43 idosos relatam não projetar a fase mais tardia de suas vidas (10 anos) e para os que o fazem os projetos são voltados para o convívio familiar e religião/espiritualidade. Segundo os idosos, os projetos são estímulos para a continuidade da vida e dentre as pessoas incluídas destacam-se cônjuge e filhos. Conclusão: Compreender como os idosos projetam o futuro nos permite refletir e recriar ações para subsidiar a concretização destes, melhorando a autonomia e a qualidade de vida na velhice.

palavras-chave

Idoso. Projetos. Metas. Envelhecimento.

\section{Introdução}

A velhice está sendo considerada a fase mais longa do desenvolvimento humano se comparada ao tempo em que as gerações anteriores viveram e, por isso, compreender como os idosos projetam o futuro para a fase mais tardia de suas vidas é um dos desafios daqueles que trabalham com sujeitos longevos. A experiência do envelhecimento é por vezes caracterizada por mudanças físicas, psicológicas e emocionais no âmbito individual e coletivo que exigem maior capacidade adaptativa do idoso para prosseguir com suas ocupações e projetos, que no decorrer do tempo se apresentam com novas facetas e roupagens (SANTANA; BELCHIOR, 2013).

No processo de envelhecimento, é comum que os sujeitos se deparem com o esvaziamento dos papéis ocupacionais que lhes dão a identidade para uma convivência social participativa e inclusiva. $\mathrm{O}$ engajamento em papéis e ocupações é um meio de suprir tais demandas individuais, que, quando atendidas, levam à realização pessoal, ao aumento do senso de autoeficácia e facilita o enfrentamento de novos desafios diários (CHRISTIANSEN et al., 1999).

Neste contexto, os projetos de vida são o desejo de transformar o cotidiano, considerando elementos importantes do passado e do presente, almejando algo melhor para o futuro. Eles se desenvolvem em uma organização multidimensional e são atravessados por aspectos objetivos e subjetivos advindos da experiência e trajetória de vida pessoal (MARCELINO; CATÃO; LIMA, 2009). 
Além disso, podem ser planejados e estruturados em diferentes esferas de tempo (curto, médio e longo prazo), espaço (concreto ou abstrato), participação (sozinho ou com outra pessoa) e importância (muito ou pouco importante) (PALYS; LITTLE, 1983).

O termo "projetos pessoais" foi proposto pelo psicólogo Little em 1983 como uma metodologia de estudo para compreender as ações e o comportamento humano em diferentes contextos, sendo definido como um conjunto de ações intencionais e inter-relacionadas que visa à realização de um objetivo pessoal. Isto se dá por meio do engajamento em papéis e ocupações diárias que levam à satisfação com a própria vida (CHRISTIANSEN et al., 1999). Projetar o futuro está inteiramente relacionado ao bem-estar e à qualidade de vida $(\mathrm{QV})$, pois serve como estruturador diário na busca pela satisfação pessoal por meio da realização de tarefas consideradas significativas para o sujeito. A QV faz referência à percepção quanto à própria vida, levando-se em consideração a cultura e os valores da sociedade em que está inserido, bem como os objetivos e expectativas de uma vida melhor (SANTOS et al., 2014).

A questão central no envelhecimento quanto à negociação da assistência e cuidado no final da vida é justamente a manutenção do poder de determinar os projetos pessoais, como um esforço para conduzir uma vida de significado e propósito até em idades avançadas, tanto para quem oferece os cuidados quanto para quem os recebe (SEALE, 1996). Diante disto, é essencial que o idoso tenha projetos que não envelheçam ou se percam nos tempos e estabeleça prioridades individuais, que além da expectativa quanto aos dias futuros, são indicativas das tarefas evolutivas que o faz pertencente da sociedade e gerenciador de seu cotidiano (SILVA; GUNTHER, 2000). Em face deste panorama, este estudo tem como objetivo identificar os projetos de vida de idosos em curto, médio e longo prazos, bem como as pessoas envolvidas neles e a percepção de importância dada pelos sujeitos.

\section{Metodologia}

Trata-se de um estudo quanti-qualitativo, exploratório e transversal, aprovado pelo Comitê de Ética em Pesquisa do Hospital das Clínicas da Faculdade de Medicina de Ribeirão Preto da Universidade de São Paulo (HC-FMRP-USP), processo número 5030/2012. Participaram do estudo 150 idosos da cidade de Ribeirão Preto, SP e região. Foram excluídos os idosos com alterações cognitivas e/ou com dependência total na realização das atividades instrumentais de vida diária. A abordagem aos possíveis participantes foi feita de maneira aleatória e em forma de convite. 
Os participantes foram recrutados em projetos de extensão universitária voltados à terceira idade desenvolvidos pela Faculdade de Medicina de Ribeirão Preto da Universidade de São Paulo. Especificamente, o convite ocorreu para os participantes das Oficinas de Jogos para Idosos, Oficina de Memória para idosos e Projeto de Inclusão Digital de Idosos que ocorrem no Espaço de Cultura e Extensão Universitária. A coleta de dados foi realizada entre os anos de 2012 e 2014.

Os instrumentos utilizados na coleta foram:

1. Mini Exame do Estado Mental (MEEM) - Traduzido e validado para o Brasil por Bertolucci et al. (1994), o teste avalia domínios cognitivos como orientação temporal, orientação espacial, registro de palavras, atenção, cálculo, recordação, linguagem e capacidade construtiva visual. A pontuação pode variar de 0 a 30 pontos, sendo que as notas de corte utilizadas neste estudo foram: analfabetos $=13$ pontos; 1 a 7 anos de escolaridade $=18$ pontos; 8 anos de escolaridade ou mais $=26$ pontos, conforme proposto por Bertolucci e colaboradores (1994);

2. Questionário Pfeffer de Avaliação Funcional (QPAF) - Traduzido para a população brasileira por Sanchez, Correa e Lourenço (2011) e validado por Dutra (2014). O teste avalia a capacidade funcional para a realização das atividades instrumentais de vida diária, tais como fazer compras, preparar alimentação, manter-se em dia com a atualidade, controlar finanças, entre outros. A pontuação varia de 0 a 30, sendo que quanto maior a pontuação, maior é a dependência do sujeito (PFEFFER et al., 1982);

3. Questionário Socioeconômico - Instrumento desenvolvido pelas pesquisadoras para caracterização da amostra no âmbito da idade, sexo, escolaridade e renda familiar baseado no questionário da Pesquisa Nacional por Amostra de Domicílio - PNAD utilizado pelo IBGE (2012);

4. Questionário de identificação dos projetos de vida na velhice-Desenvolvido pelas pesquisadoras e estruturado com perguntas abertas e fechadas para identificação dos projetos de vida no período de seis meses (curto), um ano (médio) e dez anos (longo prazo).

Para a análise de dados, foi utilizada estatística descritiva e análise de conteúdo do tipo temática e frequêncial a partir da formação de categorias de análise, conforme proposto por Bardin. Segundo a autora, “[...] a análise de 
conteúdo é uma técnica de investigação que tem por finalidade a descrição objetiva, sistemática e quantitativa do conteúdo manifesto da comunicação" (BARDIN, 1994, p. 18). Trata-se, portanto, do desmembramento do texto, dividindo-o em subgrupos para que a discussão fique mais clara sobre os diferentes aspectos abordados, facilitando o entendimento das informações mais relevantes (BARDIN, 2002).

\section{Resultados}

3.1 Caracterização dos idosos quanto à capacidade cognitiva e funcional

Os participantes não apresentaram disfunção cognitiva de acordo com os resultados do teste de rastreio Mini Exame do Estado Mental. Quanto à capacidade funcional, das 106 mulheres que participaram do estudo, 88\% são independentes para a realização das atividades instrumentais de vida diária e $22 \%$ apresenta dependência parcial principalmente nas tarefas relacionadas a fazer compras sozinhas e preparar a própria refeição. Nenhuma idosa apresentou dependência total de acordo com os resultados do Questionário Pfeffer.

Dos 44 homens participantes, 70\% apresentam independência funcional na realização das AIVD e 30\% são parcialmente dependentes, principalmente nas tarefas relacionadas ao cuidado doméstico, como a realização de compras (comida e vestuário), preparo de refeições e preparar um chá ou café. Nenhum idoso foi considerado totalmente dependente.

\subsection{Caracterização socioeconômica dos idosos}

A amostra incluiu 150 idosos, sendo 106 mulheres e 44 homens, com média de idade de 74 anos, em sua maioria casados $(n=47 \%)$, residindo com o cônjuge ( $n=47 \%)$, com cerca de seis anos de estudos $(n=58 \%)$, renda familiar mensal de até dois salários-mínimos $(\mathrm{n}=41 \%)$ - (salário-mínimo de referência $R \$ 724,00$ em 2014) e aposentados ( $n=87 \%$ ). 
Tabela 1 - Caracterização socioeconômica dos idosos. Ribeirão Preto - SP, 2014.

\begin{tabular}{|c|c|c|}
\hline Sexo & $\mathrm{n}$ & $\%$ \\
\hline Feminino & 106 & $71 \%$ \\
\hline Masculino & 44 & $29 \%$ \\
\hline Estado Civil & $\mathrm{n}$ & $\%$ \\
\hline Casado & 71 & $47 \%$ \\
\hline Viúvo & 52 & $35 \%$ \\
\hline Solteiro & 17 & $11 \%$ \\
\hline Divorciado & 10 & $7 \%$ \\
\hline Escolaridade & $\mathrm{n}$ & $\%$ \\
\hline Sem escolaridade & 15 & $10 \%$ \\
\hline Até seis anos de estudo & 87 & $58 \%$ \\
\hline Até onze anos de estudo & 21 & $14 \%$ \\
\hline Mais que 15 anos de estudo & 27 & $18 \%$ \\
\hline Renda familiar mensal $\left.\right|^{\star \star \star}$ & $\mathrm{n}$ & $\%$ \\
\hline Até dois salários-mínimos & 62 & $41 \%$ \\
\hline Até quatro salários-mínimos & 44 & $29 \%$ \\
\hline Até seis salários-mínimos & 16 & $11 \%$ \\
\hline Mais que seis salários-mínimos & 23 & $15 \%$ \\
\hline Não respondeu & 05 & $4 \%$ \\
\hline Ocupação & $\mathrm{n}$ & $\%$ \\
\hline Aposentado(a) & 131 & $87 \%$ \\
\hline Em atividade & 15 & $10 \%$ \\
\hline Pensionista & 04 & $3 \%$ \\
\hline Com quem reside & $\mathrm{n}$ & $\%$ \\
\hline Cônjuge & 70 & $47 \%$ \\
\hline Filhos & 29 & $19 \%$ \\
\hline Sozinho & 35 & $23 \%$ \\
\hline Outros parentes & 16 & $11 \%$ \\
\hline
\end{tabular}

***Salário-mínimo de referência $\mathrm{R} \$ 724,00$ em 2014.

\subsection{Quanto aos projetos de vida}

Dos 150 idosos, 41 referem não projetar o futuro, pois acreditam que os planos devem ser feitos pelos jovens, enquanto que os idosos devem apenas viver um dia de cada vez. Os demais participantes referem projetos de vida diversos que serão apresentados nos quadros a seguir. Os projetos estão divididos por tempo (curto/ médio e longo prazo) e em categorias formadas pelo agrupamento de respostas, a saber: (Quadro 1) - Saúde e bem estar físico; lazer e participação social e familiar; e (Quadro 2) - Trabalho; econômico e religioso/espiritualidade. 


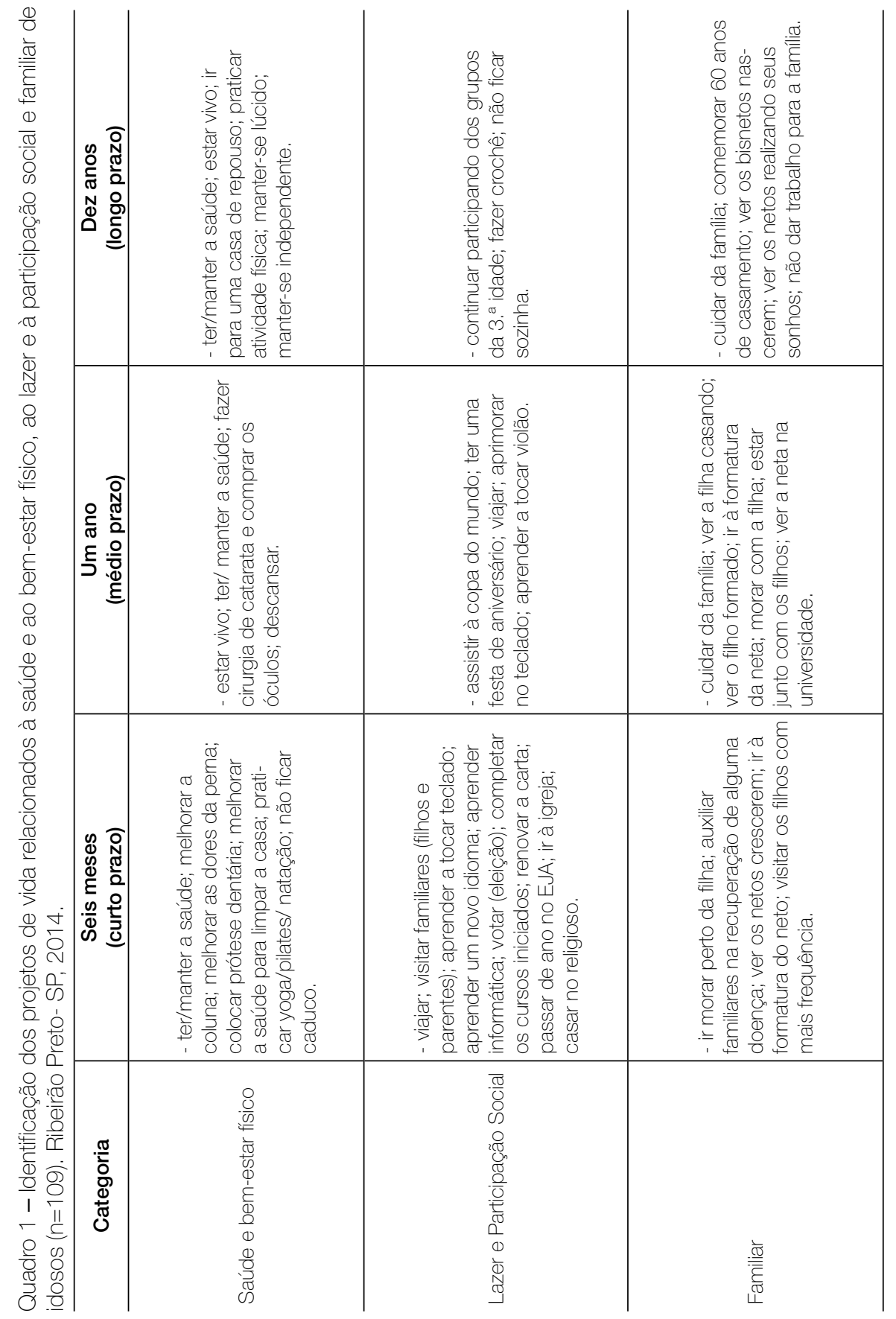

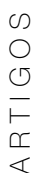

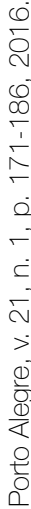

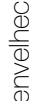

응

产

咅 


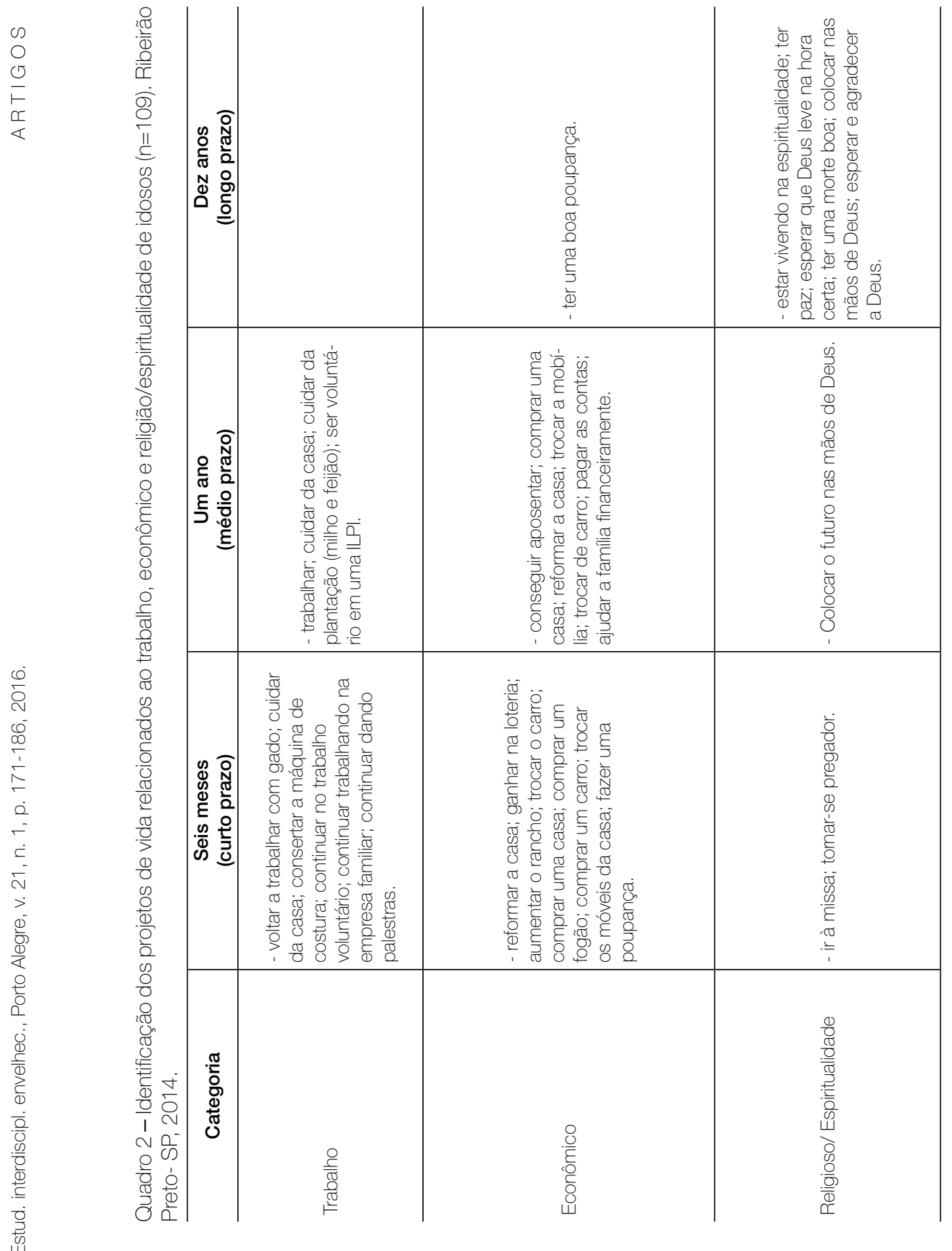


Quanto à saúde e ao bem-estar físico, no prazo de seis meses a um ano, os participantes desejam diminuir as dores articulares, passar por procedimento cirúrgico oftalmológico e melhorar a capacidade funcional, principalmente com vistas à manutenção da independência das atividades básicas e instrumentais da vida diária. Desejam manter a saúde e continuar vivos num futuro de 10 anos. Há também o interesse em ir para uma instituição de longa permanência, o que nos coloca diante da percepção de que a perda da capacidade funcional é esperada e que o cuidado pela família pode não ser possível. Há que se considerar que vários idosos temem a dependência funcional e não desejam dar trabalho às famílias.

No âmbito do lazer e da participação social, os projetos de curto prazo estão focados em viagens de turismo e também relacionados à visita a familiares que residem distante. Incluem ainda o gerenciamento do tempo livre e a preocupação em ampliar as habilidades com vistas à aquisição de novos hobbies como o artesanato, tocar teclado e aprender um novo idioma. Estes interesses irão requerer estratégias de engajamento em cursos específicos e se relacionam diretamente a projetos educacionais ou aqueles desenvolvidos em grupos para idosos. Em médio prazo, aparecem os projetos ligados à comemoração de aniversário, viagens e assistir a eventos esportivos, uma vez que especialmente no período da coleta de dados foi o ano de realização da Copa do Mundo de Futebol no Brasil. Os projetos de longo prazo se dirigem à manutenção daquilo que já estava sendo desenvolvido como, por exemplo, as atividades artesanais tais como o crochê e a continuidade na participação em grupos para idosos. Ressalta-se a importância do desejo dos participantes em não terem perdas funcionais num período de oito a dez anos, o que seria essencial para o engajamento em atividades e projetos sociais.

Nos projetos que envolvem a família, num prazo de seis a dez anos, o desejo é morar junto ou estar próximo dos familiares, cuidar e ser cuidado por seus filhos e demais parentes e participar dos eventos comemorativos como formatura, aniversários entre outros acontecimentos. Aparece ainda a preocupação com a ajuda financeira necessária a muitas famílias de baixa renda, que têm a aposentadoria do idoso como única ou principal fonte de renda familiar. A preocupação em não ser um ônus para a família em idade avançada foi apontada por alguns participantes.

Em relação ao trabalho, num período de seis a doze meses os participantes referem o interesse em reaver algumas atividades desenvolvidas no passado como, por exemplo, o manejo de animais no campo ou o trabalho formal, o cuidado com a casa ou a manutenção do trabalho voluntário já desenvolvido. Não há qualquer referência a desenvolver atividades de trabalho em longo prazo. 
Em relação aos projetos econômicos, em curto e médio prazo há o desejo de aquisição de imóveis e carros, reforma da casa, compra de eletrodomésticos e pagamento de dívidas. Em longo prazo, há menção de ter uma boa poupança para passar a velhice e deixar algo para seus familiares.

Sobre os projetos voltados à espiritualidade e à religiosidade, num prazo de seis meses há o desejo de continuar a atender a eventos religiosos em comunidade como ir à missa. Com o espaçar do tempo, os projetos se voltam ao desenvolvimento da espiritualidade como estar próximo e com a vida nas mãos de Deus. Num prazo de dez anos, 43 participantes relatam não projetar o futuro para a fase mais tardia de suas vidas. Para os que o fazem, os projetos se referem à espiritualidade suscitada pela proximidade da finitude da vida e desejam esperar ter uma boa morte e estar com Deus.

É possível notar diferenças na projeção de futuro de acordo com o sexo. Os homens têm mais objetivos pessoais relacionados aos aspectos econômicos, tais como compra e reforma de casa e carro, enquanto que os projetos de vida das mulheres são em sua maioria relacionados às categorias de lazer, participação social e convívio familiar.

Quanto às pessoas envolvidas nos projetos de vida dos idosos, 72 relatam incluir os filhos, 61 incluem o cônjuge, 46 os netos, 34 incluem os amigos e 25 apenas o próprio idoso, sendo que nesta questão era possível assinalar mais que uma alternativa como resposta. Segundo os participantes, os projetos de vida são importantes por serem maneiras de buscar algo melhor para o futuro, sendo esta a razão para seguir em frente. Além disso, relatam ser um estímulo para a continuidade da vida por meio de objetivos a serem alcançados.

\section{Discussão}

Este estudo teve como objetivo identificar os projetos de vida de idosos, bem como as pessoas envolvidas e a percepção de importância dada. O fenômeno da longevidade e a maneira como se tem vivido e projetado a velhice são temas importantes para a compreensão dos novos rearranjos sociais e familiares e como o idoso se mantém como um sujeito autônomo e desejante. O estudo dos projetos de vida é por si só o estudo de um fenômeno complexo que envolve as expectativas pessoais, sociais e familiares dos sujeitos envolvidos.

Destaca-se neste estudo a não projeção de futuro de 41 participantes. Tal resultado pode estar relacionado com vários aspectos que envolvem a fase avançada da velhice como a percepção sobre a continência e apoio familiar, a percepção de saúde e de recursos financeiros, a motivação, a capacidade e 
potência do sujeito para a concretização dos desejos e projetos, dentre outros. É necessário ter em conta que a velhice brasileira ainda é um fenômeno novo e que a experiência social vivida pelo idoso é de desempoderamento, fragilização e vitimização cultural (SOUSA; CASTRO; SÁ, 2012). Vislumbrar-se como sujeito de desejo e de potência é um desafio necessário de ser enfrentado pessoal e coletivamente. Tal panorama, embora assustador, também se encontra em processo de mudança.

A velhice por muito tempo foi considerada uma fase de perdas e restrições e, de fato, enfrentar a transitoriedade da vida pode ser um processo complexo, o que explica o fato de muitos idosos prenderem-se ao passado, deixando de desfrutar o presente e/ou projetar o futuro, o que diminui a possibilidade de atingir a autorrealização (TREVISAN et al., 2013). A autorrealização pode ser compreendida como uma forma de sucesso intrínseco individual em seu estado máximo de desenvolvimento humano, sendo esta uma forte motivação para a estruturação do cotidiano rumo a um nível mais avançado de satisfação (ARAÚJO; LEAL, 2009). O sujeito busca por meio de tarefas e papéis significativos desenvolver o seu potencial máximo enquanto ser individual e coletivo, favorecendo a satisfação pessoal, o comprometimento familiar e o orgulho de si.

Planejar o futuro em qualquer fase da vida está diretamente relacionado ao resgate da potencialidade humana na busca pela realização política, cultural, psicológica e social (LINARI, 2004). Diante disto, destaca-se a importância de oferecer oportunidades e subsídios para que o idoso consiga gerenciar o seu cotidiano e traçar objetivos pessoais com autonomia até em idades avançadas.

Nos resultados obtidos no estudo, destacam-se os projetos relacionados à família como o principal eixo estruturador das falas dos participantes. A família ancora os desejos de cuidados tanto do idoso como sujeito a ser cuidado quanto como cuidador. Isto também se torna claro diante do fato de que os projetos de vida dos idosos incluem basicamente familiares próximos tais como cônjuge, filhos e netos.

A família sem dúvidas exerce papel importante enquanto suporte emocional, cognitivo, material e social na velhice (CAMARGOS; RODRIGUES; MACHADO, 2011), porém, há de se considerar que por vezes o idoso é quem assume o papel de provedor familiar que oferece moradia e/ou condição financeira para o sustento (RABELO; NERI, 2015), possibilitando ao outro realizar seus projetos de vida por meio de sua ajuda, assim como mostram os dados deste estudo que dentre os planos futuros dos idosos estão auxiliar filhos e parentes financeiramente. Principalmente pelo fato de lidarmos neste estudo com sujeitos de baixa renda, muitas vezes o rendimento garantido é a renda advinda da aposentadoria. 
Os projetos relacionados à reforma e à aquisição de bens e imóveis também podem perpassar a preocupação em deixar um legado patrimonial ou ainda formas básicas de subsistência para os seus entes. Atualmente, os idosos tem sido importantes consumidores do mercado da construção civil e de automóveis e hoje já é possível observar maior facilidade de compra e venda para sujeitos nesta faixa etária, tais como garantia de unidades destinadas aos idosos nos programas habitacionais, unidades construídas em pavimento térreo para facilitar a locomoção e garantir maior segurança, entre outras (PORTAL BRASIL, 2016). Isto se deu pela transição do paradigma ao qual vivemos hoje com relação ao envelhecimento, pois no passado, adiante da baixa expectativa de vida na velhice, os idosos brasileiros não podiam ser candidatos a créditos, financiamentos, seguros, etc., porém hoje o idoso é visto como confiável e comprometido com as dívidas assumidas, além do aumento do poder de compra desta parcela da população (LAMBERT-PANDRAUD; LAURENT; LAPERSONNE, 2005).

Também se destacam os projetos de vida relacionados ao lazer e à participação social na velhice, que podem ser considerados potenciais geradores de uma nova sociabilidade e valorização pessoal e coletiva, uma vez que promovem integração, atualização cultural, construção de novas redes de contato e descoberta de outras habilidades e interesses (TEIXEIRA, 2007). O engajamento neste tipo de atividade na velhice pode ser facilitado pela disponibilidade de tempo livre advindo com a aposentadoria, pois o idoso se isenta dos compromissos profissionais e consegue empregar seu tempo em atividades prazerosas, aproveitando oportunidades que antes não eram possíveis concomitantes às atividades laborais (FERRARI, 2002).

Os projetos de vida relacionados à manutenção da saúde e do bem-estar físico aparecem como contínuos ao longo do tempo principalmente por estarem relacionados diretamente à vida. De fato, uma boa saúde tem importância central na conservação da autonomia e qualidade de vida, sendo estes direitos fundamentais para a manutenção da dignidade, liberdade de escolha e integridade na velhice (MOREIRA; TEIXEIRA; NOVAES, 2014). O idoso frágil fica exposto ao aumento da morbidade e ao declínio da capacidade funcional, $\mathrm{o}$ que afeta sua independência no cotidiano e sua participação social (NUNES; BARRETO; GONÇALVES, 2012). Almejar uma boa saúde é o desejo de não depender de outrem, de manter a autonomia e sentir-se vivo.

Ressalta-se o fato de uma parcela considerável da amostra não projetar o futuro em longo prazo, mesmo tendo estes sujeitos a capacidade funcional preservada para a realização das atividades da vida diária no momento da coleta de dados. Para aqueles que o fazem nota-se a preocupação em não ser 
um ônus para as famílias e contraditoriamente desejam manterem-se capazes de cuidar delas. A solução encontrada para o porvir da perda da independência é expressa pelo desejo de ir para a Instituição de Longa Permanência para Idosos, estar em paz com Deus e ter uma boa morte.

O contexto do envelhecimento amplia a vivência de perdas, mudança nos papéis sociais e ocupacionais, alterações cognitivas e fisiológicas, além da proximidade com a finitude da vida. Diante das adversidades vividas pelos idosos, a espiritualidade pode ser utilizada como ferramenta de enfrentamento na busca pelo bem-estar social. Segundo Gutz e Camargo (2013, p. 794), "[...] a espiritualidade e o envolvimento em religiões organizadas podem proporcionar aumento do senso de propósito e significado da vida, que são associados à maior capacidade do ser humano em responder de forma positiva às demandas do cotidiano".

\section{Conclusão}

O envelhecimento da população nos coloca diante do desafio da longevidade, percebida como o acréscimo a mais de anos à existência, e quiçá com mais qualidade de vida. A condição de "envelhecentes" nos convida a refletir sobre o passado, repensar o presente e programar o futuro a partir do olhar de velhos. O exercício de projetar o futuro sempre esteve a cargo das crianças, jovens e adultos. Assim, olhar para o lugar social do idoso e para seus projetos de vida nos permite tentar compreender este processo e estudar ações a serem desenvolvidas buscando a concretização destes.

O engajamento em atividades na velhice pode ser facilitado pela disponibilidade de tempo livre, pelo desejo de realizar os planos pessoais principalmente por meio de atividades prazerosas, aproveitando oportunidades que antes não eram possíveis. Por isso, projetar o futuro torna-se essencial para garantir a satisfação pessoal e a qualidade de vida até em idades bastante avançadas.

\section{LIFE PROJECTS IN THE OLD AGE}

\section{abstract}

Objectives: Identify projects of life in short, medium and long-term of elderly, who will be the people involved in this project, and the perception of importance given. Material and method: Quantitative and qualitative study exploratory and transversal. Data collection: 

naire Pfeffer; 3) socioeconomic questionnaire; and 4) Questionnaire to identifying Life Project of old Age. The data analysis was realized in a descriptive manner through context analysis. Results: 150 elderly attended the research, 106 woman and 44 men. They are 74 years old in average; 41 of them prefer not to project their future, they believe it is something that should have done by the youngers. To the ones who do it in short and medium term, we highlighted the projects related to leisure activities, social participation and family life. The health maintenance and physical well-being appears as continuous; 43 elderly, reported not to project their later stage of their lives and for those who do it, the projects are especially about the family life and religion/spirituality. According to the elderly people, the projects of life are like a stimulus to continue their life, and among the people included in that projects stand out spouse and children. Conclusion: The comprehension about how the elderly people project their future allows us to reflect and recreate actions to make their projects come true, improving autonomy and quality of life in old age.

keywords

Elderly. Projects. Goals. Aging.

\section{referências}

ARAÚJO Rodrigo; LEAL, Raimundo. O Trabalho como Recurso de Auto-Realização. In: ENCONTRO DE GESTÃO DE PESSOAS E RELAÇÕES DE TRABALHO, 2., 2009, Curitiba. Anais... Curitiba: EnGPR, 2009. p. 1-11.

BARDIN, Laurence. Análise de conteúdo. Lisboa: Edição Setenta, 1994. 226 p. Análise de conteúdo. Trad. Luís Antero Reto e Augusto Pinheiro. Lisboa, Edição Setenta, 2002

BERTOLUCCI, Paulo Henrique et al. The Mini-Mental State Examination in a general population: impact of educational status. Arquivos de Neuropsiquiatria, São Paulo, v. 52, n. 1, p. 1-7, mar. 1994.

CAMARGOS, Mirela Castro Santos; RODRIGUES, Roberto Nascimento; MACHADO, Carla Jorge. Idoso, família e domicílio: uma revisão narrativa sobre a decisão de morar sozinho. Revista Brasileira de Estudos de População, Rio de Janeiro, v. 28, n.1, p. 217-230, jan./jun. 2011

CHRISTIANSEN, Charles et al. Occupations and Well- Being: A Study of Personal Projects. The American Journal of Occupational Therapy, Rockville, MD, v. 53, n. 1, p. 91-100, Jan./Feb. 1999.

DUTRA, Marina Carneiro. Validação da Escala de Pfeffer para a população idosa brasileira. 2014. 72 f. Dissertação (Mestrado em Gerontologia) - Universidade Católica de Brasília, Brasília, 2014. 
FERRARI, Maria Auxiliadora Cursino. Lazer e ocupação do tempo livre na terceira idade. In: NETTO, Matheus Papaleo. Gerontologia: a velhice e o envelhecimento em visão globalizada. São Paulo: Atheneu, 2002, p. 98-105

GUTZ, Luiza; CAMARGO, Brigido Vizeu. Espiritualidade entre idosos mais velhos: um estudo de representações sociais. Revista Brasileira de Geriatria e Gerontologia, Rio de Janeiro, v. 16, n. 4, p. 793-804, out./dez. 2013

INSTITUTO BRASILEIRO DE GEOGRAFIA E ESTATÍSTICA, Pesquisa de orçamentos familiares 2008-2009 - POF 5 Questionário de trabalho e rendimento individual. Disponível em: <http://biblioteca.ibge.gov.br/visualizacao/instrumentos_de_coleta/ doc2622.pdf>. Acesso em: 24 out. 2012.

LAMBERT-PANDRAUD, Raphaelle; LAURENT, Gilles; LAPERSONNE, Eric. Repeat Purchasing of New Automobiles by Older Consumers: empirical evidence and interpretations. Journal of Marketing, Chicago, v. 69, n. 2, p. 97-113, Apr. 2005.

LINARI, Julia Aparecida. Programa Pré-Aposentadoria: O Recomeço de uma Nova Vida - Crise Ou Oportunidade? O Caso CESP. 2004. 196 f. Dissertação (Mestrado em Gerontologia) - Pontifícia Universidade Católica de São Paulo, São Paulo, 2004.

MARCELINO, Maria Quitéria dos Santos; CATÃO, Maria de Fátima Fernandes Martins; LIMA, Cláudia Maria Pereira. Representações Sociais do Projeto de Vida entre Adolescentes no Ensino Médio. Psicologia: Ciência e Profissão, Brasília, v. 29, n. 3, p. 544-557, 2009.

MOREIRA, Ramon Missias; TEIXEIRA, Rafael Messias; NOVAES, Karine Oliveira Contribuições da atividade física na promoção da saúde, autonomia e independência de idosos. Kairós Gerontologia, São Paulo, v. 17, n. 1, p. 201-217, mar. 2014.

NUNES, Ana Paula Nogueira; BARRETO, Sandhi Maria; GONÇALVES, Luana Giatt Relações sociais e autopercepção da saúde: projeto envelhecimento e saúde. Revista Brasileira de Epidemiologia, São Paulo, v. 15, n. 2, p. 415-428, jun. 2012.

PALYS, Ted; LITTLE, Brian. Perceived Life Satisfaction and the Organization of Personal Project Systems. Journal of Personality and Social Psychology, Washington, v. 44 n. 6, p. 1221-1230, 1983.

PFEFFER, Robert et al. Measurement of functional activities in older adults in the community. The Journal of Gerontology, Oxford, v. 37, p. 323-329, 1982

PORTAL BRASIL. Minha Casa Minha Vida tem unidades reservadas para idosos. Disponível em: <http://www.brasil.gov.br/eu-vou/minha-casa-minha-vida-tem-unidades-reservadas-para-idosos>. Acesso em: 2 maio 2016.

RABELO, Doris Firmino; NERI, Anita Liberalesso. Tipos de configuração familiar e condições de saúde física e psicológica em idosos. Cadernos de Saúde Pública, Rio de Janeiro, v. 31, n. 4, p. 874-884, abr. 2015.

SANCHEZ, Maria Angélica dos Santos; CORREA, Priscila Cristina Ribeiro, LOURENÇO, Roberto Alves. Cross-cultural Adaptation of the "Functional Activities Questionnaire FAQ" for use in Brazil. Dementia \& Neuropsychology, São Paulo, v. 5, n. 4, p. 322-327, Oct./Dec. 2011.

SANTANA, Carla da Silva; BELCHIOR, Carolina Guimarães. A velhice nas telas do cinema: um olhar sobre a mudança dos papéis ocupacionais dos idosos. Kairós Gerontologia, São Paulo, v. 16, n. 1, p. 93-116, mar. 2013.

SANTOS, Priscila Mari et al. Atividades no lazer e qualidade de vida de idosos de um programa de extensão universitária em Florianópolis (SC). Revista Brasileira de Atividade Física e Saúde, Pelotas, v. 19, n. 4, p. 494-503, 2014

SEALE, Clive. Living Alone towards the End of Life. Ageing \& Society, Cambridge, v. 16, n. 1, p. 75-91, Jan. 1996. 
SILVA, lolete Ribeiro da; GUNTHER, Isolda de Araújo. Papéis sociais e envelhecimento em uma perspectiva de curso de vida. Psicologia: Teoria e Pesquisa, Brasília, v. 16, n. 1, p. 31-40, jan./abr. 2000.

SOUSA, Ivone Félix de; CASTRO, Marli Bueno de; SÁ, Eline Alcoforado Maranhão de. A realidade social do idoso e a política de assistência social. Fragmentos de Cultura, Goiânia, v. 22, n. 1, p. 81-96, jan./mar. 2012.

TEIXEIRA, Solange Maria. Lazer e tempo livre na "terceira idade": potencialidades e limites no trabalho social com idosos. Kairós Gerontologia, São Paulo, v. 10, n. 2 , p. 169-188, dez. 2007

TREVISAN, Mauro et al. Olhares acerca da finitude em idosos. Revista Brasileira de Ciências do Enve/hecimento Humano, Passo Fundo, v. 10, n. 3, p. 271-284, set./dez. 2013.

Recebido: 04/11/2015

Aceite Final: 08/08/2016 